\title{
ZERO-VALENT IRON NICKEL MODIFIED NATURAL ZEOLITE MATERIAL: CHARACTERIZATION AND ENVIRONMENTAL ASPECT OF APPLICATION - FIRST RESULTS
}

\author{
NENAD S. KRSTIĆa,*, VLADIMIR D. DIMITRIJEVIĆa, \\ MAJA N. STANKOVIĆa, DEJAN T. DULANOVIĆa, \\ MILOŠ G. ĐORĐEVIĆa,b, MILOŠ MARINKOVIĆa, \\ DRAGAN M. ĐORĐEVIĆa
}

\begin{abstract}
The aim of this study was preparation of one low cost and environmentally friendly material for wastewater treatment toward both inorganic and organic pollutants, based on natural zeolite from one of the largest zeolite deposits in Serbia (Zlatokop, Vranjska Banja). The idea was to integrate zero-valent bimetallic FeNi particles onto zeolite, based on liquid-phase reduction method. Obtained material zvFeNi@zVB showed good sorption properties with high removal efficiency under the investigated conditions toward inorganic (M(II) heavy metal ions $\mathrm{Cu}, \mathrm{Cd}, \mathrm{Pb}, \mathrm{Zn}$ ) and organic (dyes Reactive Blue 19 and Methylene Blue) pollutants. Compared with pure FeNi material, modified zeolite (zvFeNi@zVB) showed better sorption properties and "faster clean" water from evaluated pollutants.
\end{abstract}

Keywords: low cost-, environmentally friendly- material, bimetallic zerovalent FeNi particles, zeolite, wastewater treatment.

\section{INTRODUCTION}

Water pollution by inorganic and organic hazardous materials presents serious environmental problem throughout the world. Different ways of water contamination can be produced by numerous sources (industry, agriculture, human activities). The main goal of many studies from different parts of the world was to find high efficiency material for water

\footnotetext{
a University of Niš, Faculty of Science and Mathematics, Department of Chemistry, Višegradska 33, 18000 Niš, Serbia

${ }^{b}$ PUC for water supply and sewerage "Naissus", Kneginje Ljubice 1/1, 18000 Niš, Serbia

"Corresponding author, e-mail: nenad.krstic84@yahoo.com
} 
treatment. That material must be cheap and easy to prepare, but at the same time made from some natural and widely available material or an industrial nus-product; and of course, to be environmentally friendly [1-3].

Different materials and methods for water treatments can be found in the literature, like untreated and/or the chemically modified biomasses, such as papaya wood [4], Coriandrum sativum [5], peanut hull pellets [6], sago waste [7], rice husk ash and neem bark [8], grape stalk wastes [9], Lagenaria vulgarias shell $[1,2]$ etc. Natural and chemically modified zeolites are widely used as low-cost material for water treatment due to their three-dimensional aluminosilicate framework high surface area and good ion-exchangeable capacity. Zeolite was chemically modified by acids, bases, or salts treatment and/or hydrothermally [10-14]. Recently, researchers have modified natural zeolites with inorganic salts (like iron, manganese) to enhance their affinity towards pollutants by making the surface area larger and number of active sites increased [15-17].

Materials based on zero-valent metal (for example iron, iron-nickel) particles, such as clay modification materials, have been investigated in recent years as a potential sorbent [18-22].

The goal of our study was to prepare a new low cost and environmentally friendly material based on chemically modified natural zeolite. That was done by treating natural zeolite with zero-valent, bimetallic iron-nickel particles. The natural zeolite was collected from one of the largest Serbian deposits (Zlatokop deposit near Vranjska Banja). We have chosen this zeolite because there were no data of its application in the literature (in the context of this type of the modification). Due to comparison and evaluation of its potential, beside zero-valent iron nickel zeolite (zvFeNi@zVB) material, bimetallic zerovalent iron nickel (zvFeNi) referent material was synthetized as well. After the preparation of these materials preliminary environmental application on wastewater treatment was conducted as sorption experiments of removing inorganic ( $\mathrm{M}(\mathrm{II})$ heavy metal ions $\mathrm{Cu}, \mathrm{Cd}, \mathrm{Pb}, \mathrm{Zn}$ ) and organic (anthraquinone reactive dye C.I. Reactive Blue 19 (RB 19) and Methylene Blue - MB) pollutants. Also, FTIR, SEM-EDX, XRD, and BET characterizations of new prepared materials were done.

\section{RESULTS AND DISCUSSION}

\section{Fourier Transform Infrared (FTIR) Spectrometry}

The FTIR spectra of natural zeolite (zVB), zero-valent iron-nickel (zvFeNi) material and zero-valent iron-nickel chemically modified zeolite (zvFeNi@zVB) material recorded in the wavelength region between 400 and 
$4000 \mathrm{~cm}^{-1}$ are shown in Figure 1. The FTIR spectrum of natural zeolite from Zlatokop locality (Vranjska Banja, Serbia) which is shown on Figure 1a is characterized by bands typical for alumo-silicate materials. Detailed FTIR analysis of zVB is given in our previous study [14]. The low peak (Fig. 1b) at around $3400 \mathrm{~cm}^{-1}$ belongs to stretching vibrations of $-\mathrm{OH}$ group from small trace of iron-oxide hydroxide, while adsorption peaks around 460 and 530 $\mathrm{cm}^{-1}$ correspond to $\mathrm{Fe}-\mathrm{O}$ stretching vibrations. This peaks in FTIR spectrum of zvFeNi material can be explained by air corrosion of iron $[22,23]$.

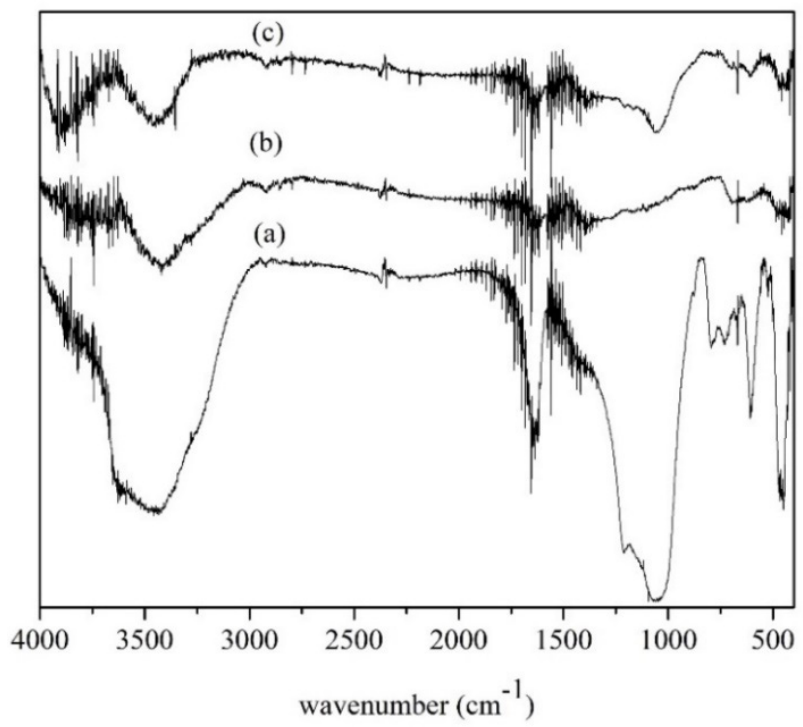

Figure 1. FTIR spectra of: (a) zVB, (b) zvFeNi and (c) zvFeNi@zVB material.

Changes in FTIR spectrum obtained from zvFeNi@zVB compared to spectra of natural zeolite (Figure 1a) are presented in Figure 1c. Intensity decrease of the adsorption peaks at around 690 and $790 \mathrm{~cm}^{-1}$ is a result of partly destruction of Si-O and Al-O bands by treatment with $\mathrm{NaBH}_{4}$ during preparation of zero-valent iron nickel particles. Good integration (loading) of FeNi particles onto natural zeolite is observed in Figure 1, where the adsorption peaks of FeNi spectrum (Figure 1b) are also appeared in zvFeNi@zVB spectrum (Figure 1c) [24].

\section{X-ray diffraction analysis}

XRD diffractograms of zvFeNi and zvFeNi@zVB samples are shown in Figure 2. As reported in our previous research, zeolite that was used in the study is good quality with clinoptilolite as dominant mineral, more than $90 \%$ 
NENAD S. KRSTIĆ, VLADIMIR D. DIMITRIJEVIĆ, MAJA N. STANKOVIĆ, DEJAN T. DULANOVIĆ, MILOŠ G. ĐORĐEVIĆ, MILOŠ MARINKOVIĆ, DRAGAN M. ĐORĐEVIĆ

(an intense peak at the $2 \theta$ angle of $22^{\circ}$ ). Also, investigated natural zeolite contained other minerals like quartz, mordenite, albite and calcite in minority [14]. According to the data from XRD diffractograms high intense peak of $2 \theta$ angle of c.a. $45^{\circ}$ indicates the presence of zero valent metals $\mathrm{Fe}^{0}$ and $\mathrm{Ni}^{0}$ in zvFeNi and zvFeNi@zVB material. Low intense peaks at about $2 \theta$ angle of $35^{\circ}$ and $65^{\circ}$ indicates a present of small amount of iron oxide hydroxide which is in accordance with FTIR data $[21,25]$.

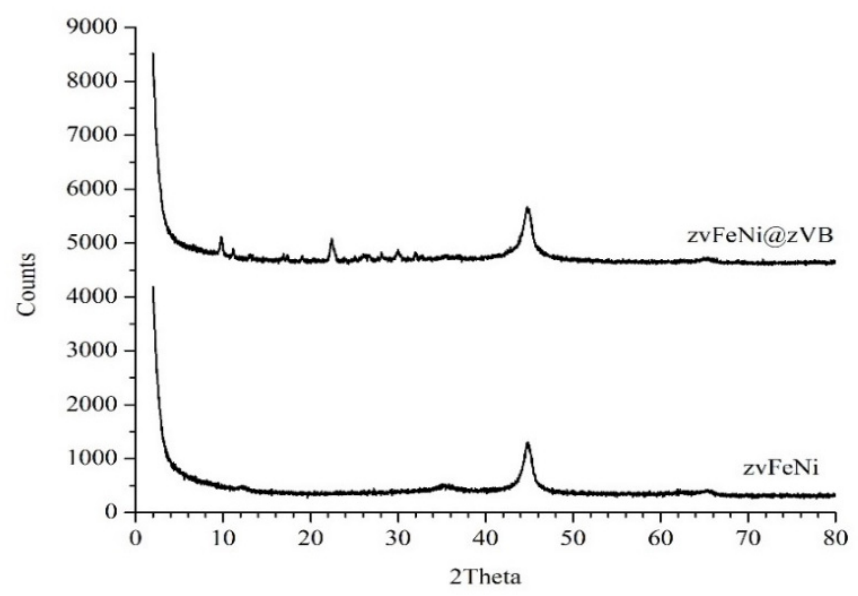

Figure 2. XRD diffractograms of: zvFeNi and zvFeNi@zVB material.

\section{Scanning electron microscopy with energy dispersive $X$-ray spectroscopy}

The morphology of obtained materials zFeNi (Figure 3a) and zvFeNi@zVB (Figure 3b) was observed by scanning electron microscopy. These micrographs show porous structure with a low agglomeration [19].

(a)

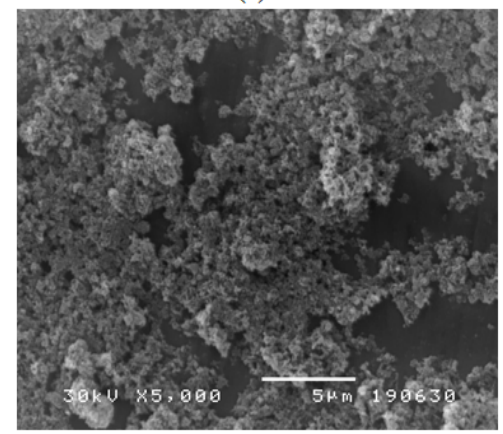

(b)

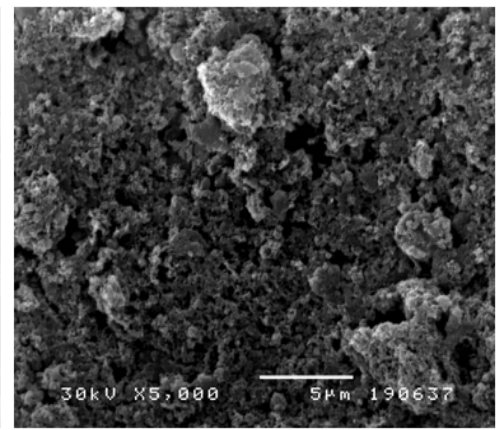

Figure 3. SEM micrographs of: (a) zvFeNi and (b) zvFeNi@zVB materials. 
The elemental composition of investigated materials was evaluated by electron dispersive X-ray analysis (Figure 4). In EDX spectrum of zvFeNi material (Figure 4a) intensive characteristic peaks for iron and nickel were identified, which confirmed bimetallic nature of obtained material. The presence of oxygen peak was a result of small iron oxidation during manipulation with material, which was in accordance with data obtained by FTIR and XRD analyses. Data from Figure $4 \mathrm{~b}$ indicate good integration of bimetallic zero-valent iron nickel particles into aluminosilicate structure of zeolite. The appearance of the peak for copper in EDX spectrum on Figure 4c indicate sorption ability (affinity) of zvFeNi@zVB toward copper(II) ion from waste waters.
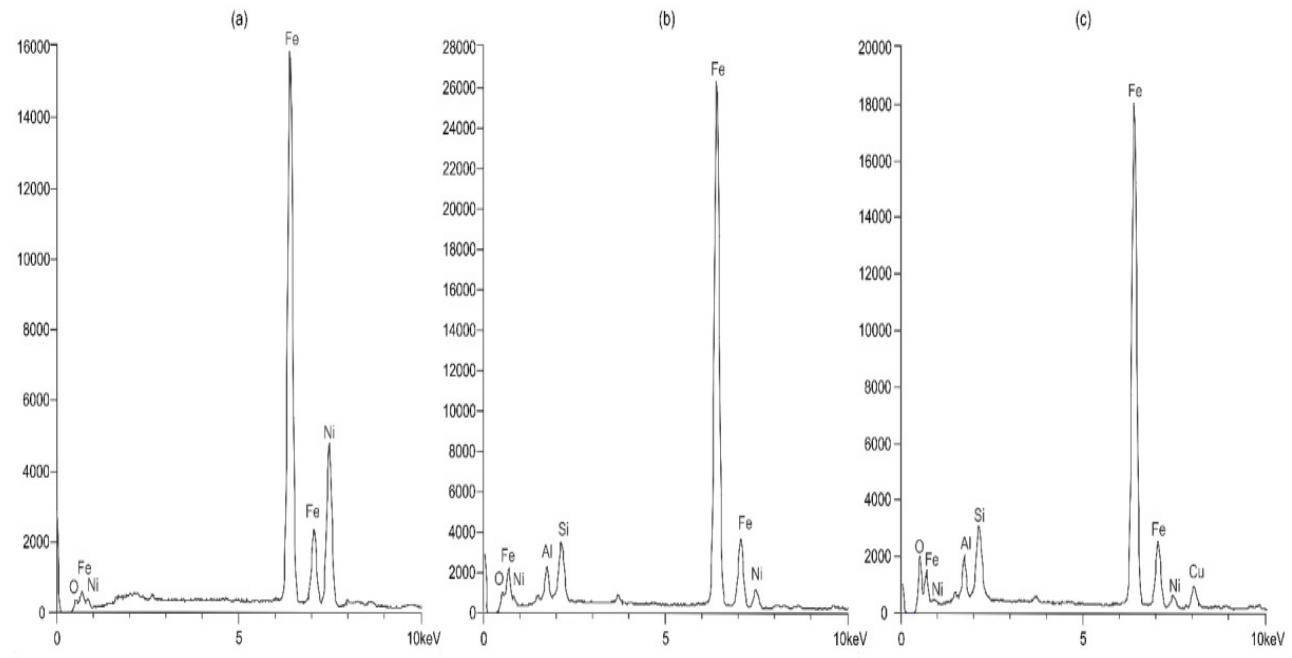

Figure 4. EDX spectra of: (a) zvFeNi, (b) zvFeNi@zVB material and (c) zvFeNi@zVB material after treatment of Cu contaminated water

\section{Environmental aspect of obtained materials - preliminary sorption results}

The effect of contact time on the residual concentration of analyzed inorganic and organic pollutants, in aqueous solution with zvFeNi and zvFeNi@zVB material is shown in Fig. 5. Experiments were performed with model wastewater system at an initial concentration of $50.0 \mathrm{mg} \mathrm{dm}^{-3}$, a sorbent dose of $4.0 \mathrm{~g} \mathrm{dm}^{-3}$, at $20 \pm 0.5^{\circ} \mathrm{C}$ and $\mathrm{pH} 5.0$. 
NENAD S. KRSTIĆ, VLADIMIR D. DIMITRIJEVIĆ, MAJA N. STANKOVIĆ, DEJAN T. DULANOVIĆ, MILOŠ G. ĐORĐEVIĆ, MILOŠ MARINKOVIĆ, DRAGAN M. ĐORĐEVIĆ
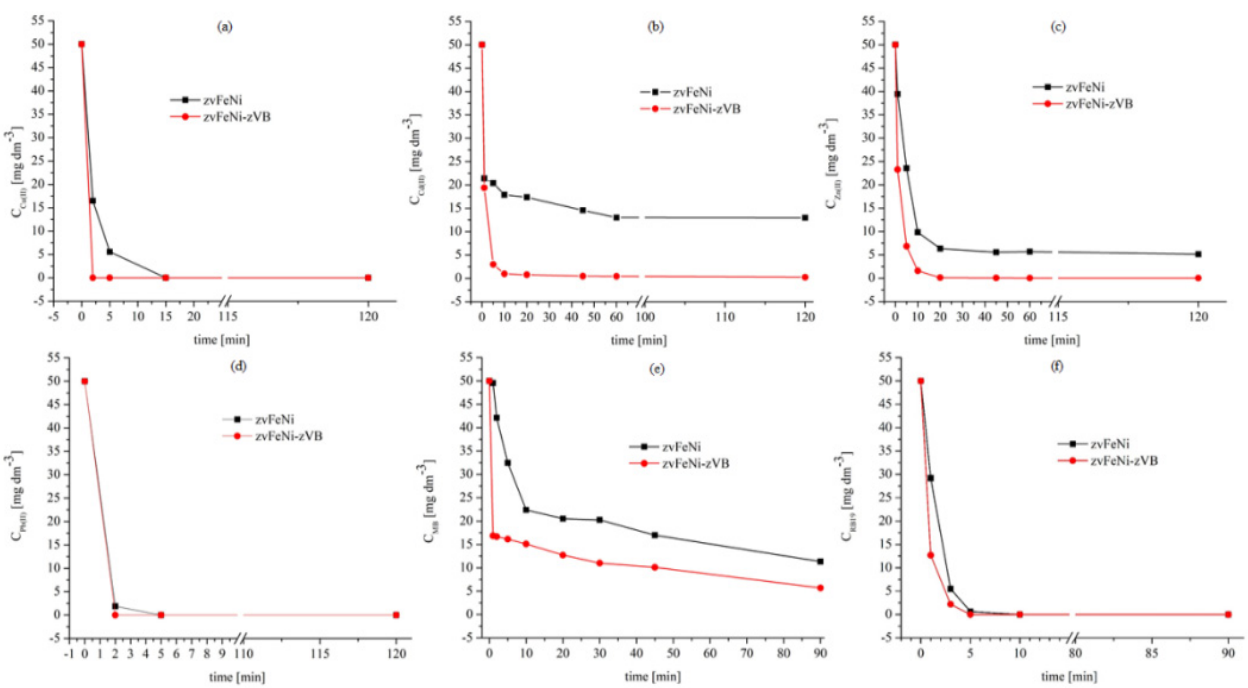

Figure 5. Effect of contact time on removal: (a) $\mathrm{Cu}(\mathrm{II})$ ion, (b) $\mathrm{Cd}(\mathrm{II})$ ion, (c) $\mathrm{Zn}$ (II) ion, (d) Pb(II) ion, (e) MB and (f) RB19 by zvFeNi (ロ) and zvFeNi@zVB (•) material.

The adsorption capacity, $q_{\mathrm{e}}\left[\mathrm{mg} \mathrm{g}^{-1}\right]$, and removal efficiency, $R E[\%]$, of the investigated materials calculated according to equation (1) and (2) are shown in Figure 6.

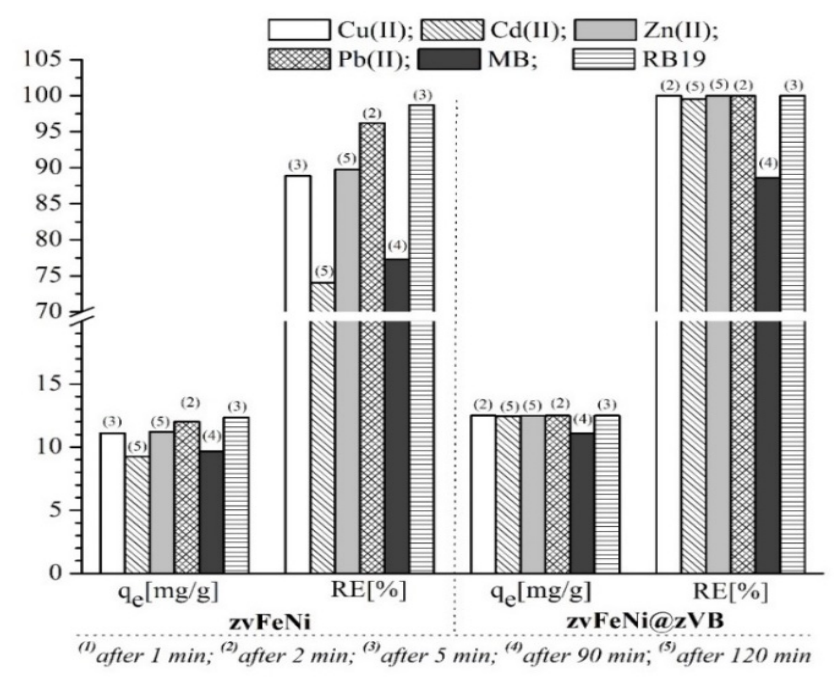

Figure 6. The adsorption capacity and removal efficiency of zvFeNi and zvFeNi@zVB material toward investigated pollutants in aqueous solution 
These preliminary results, based on data from Figures 5 and 6 , indicate that zero-valent iron-nickel (zvFeNi) and zero-valent iron-nickel modified natural zeolite (zvFeNi@zVB) materials showed good sorption properties toward investigated pollutants. Both materials were very efficient toward copper(II) and lead(II) ions. After five minutes zvFeNi removal efficiency toward $\mathrm{Cu}(\mathrm{II})$ was $88.90 \%\left(\mathrm{q}_{\mathrm{e}}=11.11 \mathrm{mg} \mathrm{g}^{-1}\right)$ and it totally removed this ion after fifteen minutes $(\mathrm{RE}=100 \%)$, while zvFeNi@zVB material showed better sorption characteristics (faster remove this heavy metal ion) and after two minutes completely removed $\mathrm{Cu}(\mathrm{II})$ ion from aqueous solution, $\mathrm{RE}=100 \%$ and $\mathrm{q}_{\mathrm{e}}=12.50 \mathrm{mg} \mathrm{g}^{-1}$. In the case of $\mathrm{Pb}(\mathrm{II})$ ion zvFeNi@zVB showed the same properties like in the situation of removing $\mathrm{Cu}(\mathrm{II})$ ion $\left(\mathrm{RE}=100 \%\right.$ and $\mathrm{q}_{\mathrm{e}}=$ $12.50 \mathrm{mg} \mathrm{g}^{-1}$ ), while the zvFeNi material showed better removal properties toward $\mathrm{Pb}$ (II) than $\mathrm{Cu}(\mathrm{II})$ ion, and totally removed it after five minutes. Material zvFeNi is potentially good sorbent to "clean" water from cadmium(II) and zink(II) ions $\mathrm{RE}_{\mathrm{Cd}(\mathrm{II})}=74.05 \%$ and $\mathrm{RE}_{\mathrm{Zn}(\mathrm{II})}=89.76 \%\left(\mathrm{q}_{\mathrm{e}(\mathrm{Cd}(\mathrm{II}))}=9.26 \mathrm{mg} \mathrm{g}^{-1}\right.$ and $\left.\mathrm{q}_{\mathrm{e}(\mathrm{Cd}(\mathrm{II}))}=11.22 \mathrm{mg} \mathrm{g}^{-1}\right)$, but zeolite modified with zero-valent iron-nickel particles showed better cleaning properties toward these heavy metal ion $\mathrm{RE}_{\mathrm{Cd}(\mathrm{II})}=99.54 \%$ and $\mathrm{RE}_{\mathrm{Zn}(\mathrm{II})}=99.97 \%\left(\mathrm{q}_{\mathrm{e}(\mathrm{Cd}(\mathrm{II}))}=12.44 \mathrm{mg} \mathrm{g}^{-1}\right.$ and $\mathrm{q}_{\mathrm{e}(\mathrm{Cd}(\mathrm{II}))}=$ $\left.12.497 \mathrm{mg} \mathrm{g}^{-1}\right)$. Investigated materials showed good removal efficiency toward methylene blue $77.31 \%\left(\mathrm{q}_{\mathrm{eMB}}=9.66 \mathrm{mg} \mathrm{g}^{-1}\right) \mathrm{zvFeNi}$ and $88.60 \%\left(\mathrm{q}_{\mathrm{eMB}}=11.07\right.$ $\mathrm{mg} \mathrm{g}^{-1}$ ) zvFeNi@zVB. In the case of reactive blue 19 zvFeNi@zVB removed $95.6 \%$ after three minutes, and $100 \%$ after five minutes, while zvFeNi removed $98.70 \%$ after five minutes and totally removed RB19 after 10 minutes. Material obtained as modification of zeolite with zero-valent metals showed better sorption properties than material which contained only zero-valent iron-nickel particles. Also, zvFeNi@zVB material faster removed some pollutants from water than zvFeNi material (Figures 5 and 6), probably due to high surface area and porous and rigid structure of zeolite [26, 27].

Since these were preliminary sorption tests, zvFeNi@zVB material will be further examined under different experimental conditions (contact time, $\mathrm{pH}$ of solution, pollutant concentration, particle size of zeolite, temperature, dose of sorbent etc).

\section{Surface Area Analysis Using the Brunauer-Emmett-Teller Method}

The textural properties of the zvFeNi and zvFeNi@zVB material (BET surface area, BJH cumulative desorption pore volume and average pore diameter) are shown in Table 1. These textural properties could be important characteristics for the sorption properties of investigated materials, because they can affect the sorption efficiency of selected pollutants. 
NENAD S. KRSTIĆ, VLADIMIR D. DIMITRIJEVIĆ, MAJA N. STANKOVIĆ, DEJAN T. DULANOVIĆ, MILOŠ G. ĐORĐEVIĆ, MILOŠ MARINKOVIĆ, DRAGAN M. ĐORĐEVIĆ

Table 1. Textural properties of the zvFeNi and zvFeNi@zVB material

\begin{tabular}{|c|c|c|c|}
\hline Material & $\begin{array}{c}\text { BET surface } \\
\text { area } \mathbf{S}_{\mathrm{BET}} \\
\left(\mathbf{m}^{\mathbf{2}} \mathbf{g}^{-1}\right)\end{array}$ & $\begin{array}{c}\text { Average pore } \\
\text { diameter }(\mathbf{n m})\end{array}$ & $\begin{array}{c}\text { BJH cumulative } \\
\text { desorption } \\
\text { pore volume }\left(\mathbf{c m}^{\mathbf{3}} \mathbf{g}^{-1}\right)\end{array}$ \\
\hline $\mathrm{zVFeNi}$ & 85.74 & 9.87 & 0.30 \\
\hline $\mathrm{zvFeNi@zVB}$ & 56.34 & 11.33 & 0.22 \\
\hline
\end{tabular}

The determined textural properties of the analyzed samples, indicates that zvFeNi sample has a slightly larger BET specific surface area $\left(85.74 \mathrm{~m}^{2} \mathrm{~g}^{-1}\right)$ and BJH cumulative desorption pore volume $\left(0.30 \mathrm{~cm}^{3} \mathrm{~g}^{-1}\right)$ compared to the zvFeNi@zVB sample BET (56.34 $\left.\mathrm{m}^{2} \mathrm{~g}^{-1}\right)$ and BJH $\left(0.22 \mathrm{~cm}^{3} \mathrm{~g}^{-1}\right)$, also zvFeNi sample has a slightly smaller average pore diameter $(9.87 \mathrm{~nm})$ compared to the zvFeNi@zVB sample (11.33 nm). These differences in BET surface area between obtained materials are probably due to size of powdered zeolite particles compared to obtained clear zvFeNi particles. Despite a little difference in textural properties both material are very efficient toward sorption of the investigated pollutants. Additionally, we also suggest that improvements of the adsorption activity of the mentioned zvFeNi@zVB sample were obtained. Improvements were done in a way to synergism physico-chemical properties such as greater pore diameter, more favorable composition of crystal phases, and potentially greater number of active sites as well as the absence of internal and/or external diffusion restrictions under the selected process parameters.

The $\mathrm{N}_{2}$ adsorption/desorption isotherms of the analyzed samples showed a typical s-shape behavior of IV-type with a type-H3 of hysteresis loop that indicated the existence of mesopores (Figure 7). The characteristic presence of this type of hysteresis loop, can be attributed to multilayer adsorption followed by capillary condensation, and, where additionaly, aggregates particles forming slit-like pores [14,27].
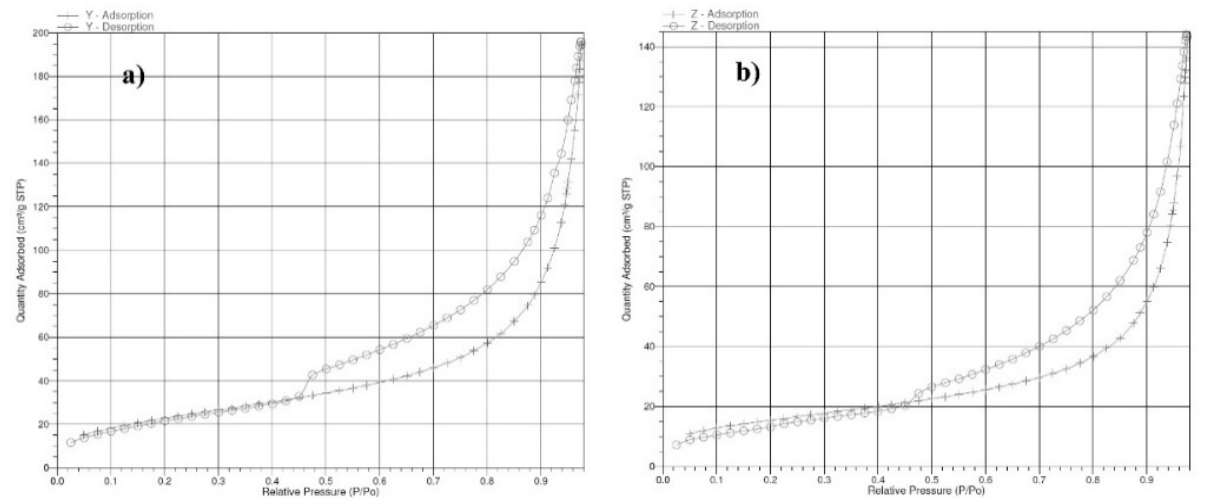

Figure 7. $\mathrm{N}_{2}$ adsorption/desorption isotherm of: a) zvFeNi and

b) zvFeNi@zVB material 
The pore system of samples was in the meso-pores range, with pores characterized with maxima in pore size between 30-35 nm for sample zvFeNi, and maxima in pore size between 30-40 nm for sample zvFeNi@zVB (Figure 8). According to the BJH desorption isotherms (Figure 8) average pore diameter for zvFeNi and zvFeNi@zVB samples were around $10 \mathrm{~nm}$ in size and $11 \mathrm{~nm}$ in size respectively.
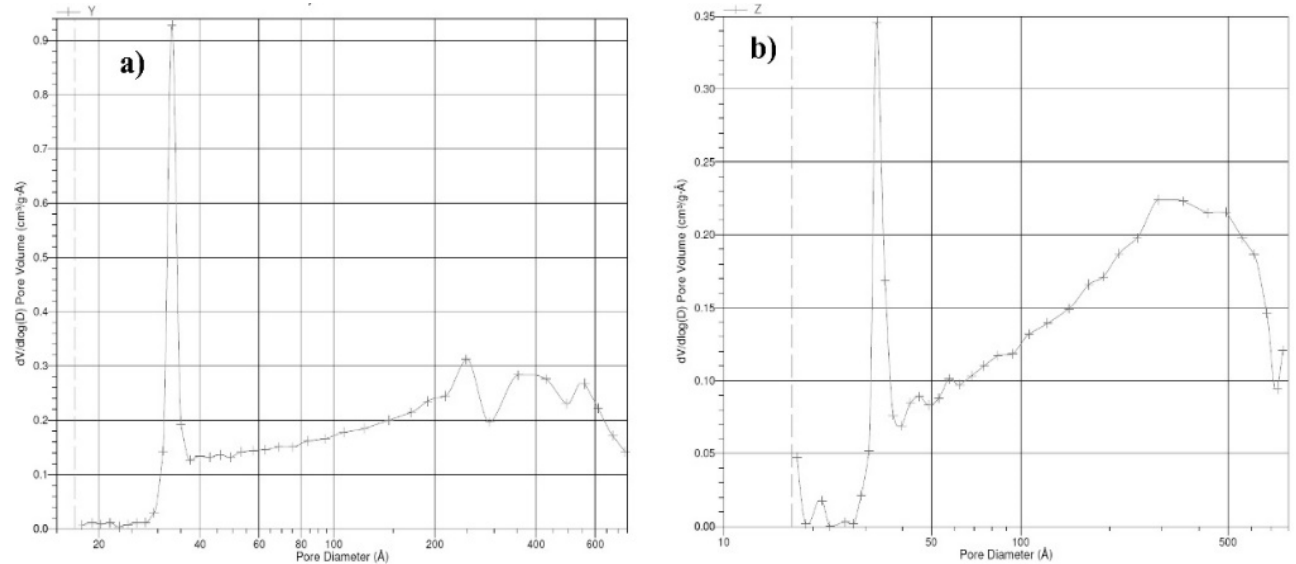

Figure 8. Pore size distribution of: a) zvFeNi and b) zvFeNi@zVB material

\section{CONCLUSIONS}

According to the data obtained with FTIR, XRD, SEM-EDX and BET good integration of bimetallic zero-valent iron nickel particles onto alumosilicate structure of natural zeolite was achieved. Obtained material (zvFeNi@zVB) showed porous structure with the pore system in a mesopore range. zvFeNi@zVB material showed good sorption affinities for both inorganic and organic investigated water pollutants. Compared to $\mathrm{FeNi}$ material, zvFeNi@zVB remove investigated pollutants faster and with very high removal efficiency. Based on BET data both materials showed s-shape behavior of IV-type with type-H3 of hysteresis loop, which can be attributed to multilayer adsorption. Since these preliminary sorption tests showed good results and obtained material zvFeNi@zVB is low cost and environmental friendly, it will be further examined under different experimental conditions (contact time, $\mathrm{pH}$ of solution, pollutant concentration, particle size of zeolite, temperature, dose of sorbent etc.) toward inorganic and organic water pollutants. 
NENAD S. KRSTIĆ, VLADIMIR D. DIMITRIJEVIĆ, MAJA N. STANKOVIĆ, DEJAN T. DULANOVIĆ, MILOŠ G. ĐORĐEVIĆ, MILOŠ MARINKOVIĆ, DRAGAN M. ĐORĐEVIĆ

\section{EXPERIMENTAL SECTION}

\section{Materials and chemicals}

Natural zeolite (zVB) was sampled from Zlatokop deposit (located in south-eastern Serbia, near the place Vranjska Banja) [14]. The raw zeolite was grounded in ball mill until it became powder, and then washed with deionized water on shaker and dried in oven overnight at $105^{\circ} \mathrm{C}$.

Used chemicals were p.a. grade, $\mathrm{FeCl}_{3} \times 6 \mathrm{H}_{2} \mathrm{O}, \mathrm{NiSO}_{4} \times 6 \mathrm{H}_{2} \mathrm{O}, \mathrm{NaBH}_{4}$ and obtained from Merck K.G.A (Darmstadt, DE), while ethanol was obtained from Zorka Pharma (Serbia). All solutions were prepared with deionized water (18M 2 ).

\section{Synthesis of zero-valent iron-nickel (zeolite) materials}

The zvFeNi@zVB and zvFeNi materials were prepared based on liquid-phase reduction method by Shi et al. [20] and Weng et al. [21]. Iron and nickel solution $7.1 \times 10^{-1} \mathrm{M}$ and $7.1 \times 10^{-1} \mathrm{M}$ respectively, were prepared by dissolving exact mass of their salts in $30 \mathrm{~mL} \mathrm{H}_{2} \mathrm{O}: \mathrm{EtOH}(1: 4 \mathrm{v} / \mathrm{v})$ solution. Solution was then shaking for half hour under the nitrogen atmosphere. After that, $2 \mathrm{~g}$ of powdered and prepared natural zeolite (washed with deionized water) was added to iron-nickel solution and shook for 15 minutes. Freshly prepared $1.1 \mathrm{M} \mathrm{NaBH}_{4}$ solution was added drop by drop until complete reduction in system was done. All the time during the reduction process solution was shaking under the nitrogen atmosphere.

\section{Characterization of zero-valent iron-nickel (zeolite) materials}

\section{Fourier Transform Infrared (FTIR) Spectrometry}

The FTIR spectra of samples were obtained by using $\mathrm{KBr}$ pellets with Fourier transform infrared spectrometer Bomem Hartmann \& Braun MB-100 spectrometer, in the wavelength range $4000-400 \mathrm{~cm}^{-1}$.

\section{X-ray diffraction (XRD) analysis}

Zeolite samples were finely ground using a mortar and pestle and placed into standard sample holders. Data was collected with a Bruker D8 Advance X-ray Diffractometer (Bruker, Germany) in theta-theta geometry in reflection mode with $\mathrm{Cu} \mathrm{Ka}$ radiation. Data collection was between $5-70^{\circ} 2 \theta$, step size of $0.02^{\circ}$ and a counting time of 1 second per step. Scanning electron microscopy with energy dispersive X-ray spectroscopy (SEM-EDX)

The morphology and elemental information of investigated samples were analyzed by scanning electron microscope (SEM JEOL-JSM 5300) equipped with energy dispersive X-ray analysis spectrometer (EDS -QX 2000S system). 

AND ENVIRONMENTAL ASPECT OF APPLICATION - FIRST RESULTS

\section{Surface Area Analysis Using the Brunauer-Emmett-Teller (BET) Method}

The specific surface area was measured by a nitrogen adsorption using the Micromeritics Gemini 5 Surface Area Analyzer, USA.

\section{Environmental aspect of application}

Environmental aspect of application, preliminary sorption abilities of zero-valent iron-nickel (zvFeNi) material and zero-valent iron-nickel chemically modified zeolite (zvFeNi@zVB) material were investigated in waste water model system with $\mathrm{M}(\mathrm{II})$ heavy metal ions ( $\mathrm{Cu}, \mathrm{Pb}, \mathrm{Cd}, \mathrm{Zn}$ ) as described in our previous investigations. The dropping concentrations of $\mathrm{Cu}(\mathrm{II}), \mathrm{Pb}(\mathrm{II}), \mathrm{Cd}(\mathrm{II})$ and $\mathrm{Zn}(\mathrm{II})$ ion in the solution during time were determined by using an atomic absorption spectrophotometer (AASAnalyst 300, Perkin-Elmer, USA), after filtration through a $0.45 \mu \mathrm{m}$ membrane filter (Agilent Technologies, Germany) [1-3].

Content of organic industrial colours RB19 and MB in the samples was determined at $592 \mathrm{~nm}$ and $660 \mathrm{~nm}$, respectively, using the UV-Vis technique by the spectrophotometer Shimadzu UV-vis 1650 PC (Shimadzu, Japan), after filtration through a $0.45 \mu \mathrm{m}$ membrane filter (Agilent Technologies, Germany) $[29,30]$.

The adsorption capacity of the investigated materials, qe [mg g-1], at equilibrium was calculated as:

$$
q_{e}=\frac{\left(C_{0}-C_{e}\right) \times V}{m}
$$

where qe is the amount of pollutant (M(II)-ion or organic colour) adsorbed per unit weight of the adsorbent, $\mathrm{V}$ is the volume of solution, $\mathrm{C} 0$ is the initial concentration of pollutant $\left[\mathrm{mg} \mathrm{dm}^{-3}\right], \mathrm{Ce}$ is the equilibrium pollutant concentration [mg dm-3], and $\mathrm{m}$ is the mass of the adsorbent [g].

The metal removal efficiency, RE [\%], of the investigated materials was estimated according to the following equation:

$$
R E=\frac{\mathrm{C}_{0}-\mathrm{C}_{\mathrm{e}}}{\mathrm{C}_{0}} \times 100
$$

where $\mathrm{C} 0$ and $\mathrm{Ce}$ are the initial and equilibrium concentrations [mg dm-3] of pollutant in solution, respectively.

\section{ACKNOWLEDGEMENTS.}

This work was supported by the Ministry of Education, Science and Technological Development of the Republic of Serbia, Contract No. 451-039/2021-14/200124. Experimental work was completed at Faculty of Sciences and Mathematics, University of Niš, Serbia. 
NENAD S. KRSTIĆ, VLADIMIR D. DIMITRIJEVIĆ, MAJA N. STANKOVIĆ, DEJAN T. DULANOVIĆ, MILOŠ G. ĐORĐEVIĆ, MILOŠ MARINKOVIĆ, DRAGAN M. ĐORĐEVIĆ

\section{REFERENCES}

1. M.N. Stanković; N.S. Krstić; I.J. Slipper; J.Z. Mitrović; M.D. Radović; D.V. Bojić; A.L. Bojić; Aust. J. Chem., 2013, 66, 227-236.

2. M.N. Stanković; N.S. Krstić; J.Z. Mitrović; S.M. Najdanović; M.M. Petrović; D.V. Bojić; V.D. Dimitrijević; A.L. Bojić; New J. Chem., 2016, 40, 2126-2134.

3. V.D. Dimitrijević; M.N. Stanković; D.M. Djordjević; I.M. Krstić; M.G. Nikolić; A. Lj. Bojić; N.S. Krstić; Stud. U. Babes-Bol. Che., 2019, 64(1), 19-39.

4. A. Saeed; M.W. Akhter; M. Iqbal; Sep. Purif. Technol., 2005, 45, 25-31.

5. D. Karunasagar; M. V. Krishna; S. V. Rao; J. Arunachalam; J. Hazard. Mater., 2005, 118, 133-139.

6. P.D. Johnson; M.A. Watson; J. Brown; I.A. Jefcoat; Waste Manage, 2002, 22, 471-480.

7. S.Y. Quek; D.A.J. Wase; C.F. Forster; Water SA, 1998, 24, 251-256.

8. A.K. Bhattacharya; S.N. Mandal; S.K. Das; Chem. Eng. J., 2006, 123, 43-51.

9. I. Villaescusa; N. Fiol; M. Martínez; N. Miralles; J. Poch; J. Serarols; Water Res., 2004, 38, 992-1002.

10. G. Yuan; H. Seyama; M. Soma; B.K.G. Theng; A: Tanaka; J. Environ. Sci. Heal. A, 1999, 34, 625-648.

11. H. Cui; L.Y. Li; J.R. Grace; Water Res., 2006, 40, 3359-3366.

12. S. Wang; Y. Peng; Chem. Eng. J., 2010, 156, 11-24.

13. I. Elaiopoulos; T. Perraki; E. Grigoropoulou; Micropor. Mesopor. Mat., 2010, 134, 29-43.

14. N.S. Krstić; M.N. Stanković; D.M. Đorđević; V.D. Dimitrijević; M.M. Marinković; M.G. Đorđević; A.L. Bojić; Bulg. Chem. Commun., 2019, 51, 394-399.

15. M.K. Doula; Water Res., 2006, 40, 3167-3176.

16. M.J. Jimenez-Cedillo; M.T. Olguín; C. Fall; J. Hazard. Mater., 2009, 163, 939-945.

17. Z. Li; J. Jean; W. Jiang; P.H. Chang; C.J. Chen; L. Liao; J. Hazard. Mater., 2011, 187, 318-323.

18. A. Ghauch; A. Tuqan; H.A. Assi; Environ. Pollut., 2009, 157, 1626-1635.

19. H. Kang; Z. Xiu; J. Chen; W. Cao; Y. Guo; T. Li; Z. Jin; Environ. Technol., 2012, 33, 2185-2192.

20. I.N. Shi; X. Zhang; Z.L. Chen; Water Res., 2011, 45, 886-892.

21. X. Weng; S. Lin; Y. Zhong; C. Zuliang; Chem. Eng. J., 2013, 229, 27-34.

22. X. Weng; Zh. Chen; Zu. Chen; M. Megharajc; R. Naiduc; Colloids Surf. A Physicochem. Eng. Asp., 2014, 443, 404-409.

23. P.K. Raul; R.R. Devi; I.M. Umlong; S. Banerjee; L. Singh; M. Purkait; J. Nanosci. Nanotechno., 2012, 12, 3922-3930.

24. D.M. Djordjević; M.N. Stanković; M.G. Djordjević; N.S. Krstić; M.A. Pavlović; A.R. Radivojević; I.M. Filipović; Stud. U. Babes-Bol. Che., 2019, 57(4), 39-54.

25. Z. Fang; X. Qiu; J. Chen; X. Qui; J. Hazard. Mater., 2011, 185, 958-969.

26. E. Alvarez-Ayuso; A. Garcia-Sanchez; X. Querol; Water Res., 2003, 37, 4855-4862.

27. X. Li; C. Lin; Y. Wang; M. Zhao; Y. Hou; Procedia Environ. Sci., 2010, 2, 1598-1612.

28. E. Kouvelos; K. Kesore; T.A. Steriotis; H.P. Grigoropoulou; D. Bouloubasi; N. Theopilou; S. Tzintzos; N. Kanelopoulos; Microp. Mesopor. Mat., 2007, 99, 106-111.

29. I.Z. Momčilović; M.M. Purenović; M.N. Miljković; A.L. Bojić; M. Randjelović; Hem. Ind., 2011, 65, 123-129.

30. I.D. Radović; J.Z. Mitrović; D.V. Bojić; M.D. Antonijević; M.M. Kostić; R.M. Baošić; A.L. Bojić; Water SA, 2014, 40, 1-18. 